98 ; tongue corered with a white fur; catamenia absent. There was considerable febrile excitement, requiring the use of salines and mild aperients up to the 27th of April, when I made the following note :Puerile respiration beneath the left clavicle; bronchial respiration beneath the right, accompanied by dulness, and increase of rocal resonance.

R. Ferri Iodid, gr. iss.; Tinct. Cardam. Co., dr. ss.; Aquæ Menthæ Piper., oz. j. M. Fiat haust. ter quotidie sumendus.

She continued to take these draughts till the 2 nd of June, when they were discontinued in consequence of epistaxis having occurred; and the cough, dyspnœa, and night sweats, being troublesome.

R. Tinct. Digitalis, M. viij; Acid. Sulph. Dil., M. x.; Tinct. Camph. Co., M. xx.; Aquæ, oz.j. M. Fixt haustus bis quotidie sumendus.

R. Pil. Aloes cum Myrrh, gr. ij. ; Pil. Ferri, gr. iij. M. Fiat pilula omni nocte sumenda.

June 30th. Improving.

Rept. omnia.

R. Liniment, Acid. Acetici., oz. ij. ; affric. dr. j.; infra claviculam dextram.

July 28th. Finding the circulation less excited, I substituted the following draught :-

R. Quinæ Sulphatis, Ferri Sulph., utrq. gr. Acid. Sulphh. dil., M. x. ; Tinct. Camph. Co., dr. ss.; Aquæ, oz.j. M. Sumat bis indies.

August 25th. Rept. haustus et augeatur Sulph. Ferri ad granum sing. haustibus.

September 8th. The catamenia have appeared for the first time. After this all her symptoms improved considerably, the night sweats disappeared, and she increased in flesh; there was still slight congh; there was, (if I may use the expression,) a cessation of hostilities to such an extent, that the patient's mother, contrary to my injunctions, begged to have her discharged.

When we speak of consumption, we are too apt to lose sight of the fact, that under one name, many varieties of disease are included, holding, it is true, many symptoms in common, yet possessing sufficiently distinctive characters to admit of, and entitle them to, a distinct classification. Some of the rarieties are more, and some less, amenable to the treatment, and although in all cases we have more reason to exercise our fears than our hopes, it is unquestionable that there are many cases in which the disease, if not cured, is at least suspended. Under the use of well-directed lietetic and medicinal treatment, and where these measures have been seconded by a residence in a uniform mild temperature, life has been prolonged to an ordinary average.

I have given the foregoing three examples, not for the purpose of founding a classification on them, but the better to enable me to convey correct ideas of those forms of the disease in which $I$ have found treatment of advantage.

The chlorotic variety is that in which you bure chlorosis united with pulmonary symptoms.

The strumous, where you have the tangible signs of scrofula existing, with evidence of pulmonary disease.

The bronchitic, where you have the bronchitis localized in the upper portion of the lung, and accompanied by dulness:
As I have already said, all the varieties have many symptoms in common, but each possesses a leading character, that at once determines the great object to be kept in view, in selecting our remedies. If some division of this kind were more universally acknowledged, it would remore from the consumptioncurers the semblance of excuse, for recommending such hosts of useless remedies, as each in his day, attempts to palm upon the profession and the public. In sketching the outlines of these varieties, I have briefly referred to the evidence of pulmonary disease. I have done so, under the belief that all who speak of consumptive disease, allude only to that which stands the test of the stethoscopic and rational evidence. I have met with the disease in three other forms-the acute, the chronic, (or more properly the acutochronic,) and the hæmoptysic, all of which have resisted the best directed efforts for their relief.

Of the acute I saw a case fatal within fourteen days. I am aware that bæmoptysis is a frequent attendant upon the disease in all its varieties; but that which I mean to designate as the hæmoptysic is that in which a copious pulmonary hæmorrhage, (recurring several times,) gives the first notice of alarm. So insidious is the pulmonary disease in many cases, that in females the hæmorrhage is regarded as vicarious, should there be any derangement of the menstrual secretion. I beg not to be misunderstood; I have seen the hæmorrhage arrested, and a deceptive calm ensue for some weeks; but it is only that calm that precedes a storm. If not fatal in all cases, the exception is a thing more to be surprised at than hoped for.

The treatment of consumption may be conducted by tonics, sedatives, and counter-irritants; but the result, if application has been timely made, will depend upon the practical tact of the attendant, and the proper administration of the remedies, so that each may be given, as it were, in season. As for instance, if much febrile excitement existed, no one would think of giviug tonics till this was subdued, although the general state of the system may urgently demand them. It is a great recommendation of even a routine tonic treatment, that a deteriorated state of the blood is present in nearly all cases of consumption; in some the cause, and in others the consequence of the disease. The preparations of iron are very valuable tonics, but in consequence of their exciting property they are indifferently borne. I think I have seen the addition of digitalis and nitrate of potass eminently valuable in reconciling the system to its use. I have tried naphtha in many, cases, but bave only found it of advantage in the bronchitic variety. Should it, howerer, prove as useful in this variety in the hands of others as it has in mine, I think that my friend Dr. John Hastings will not be undeserving the thanks of the profession for having introduced it to their notice.

(To be continued.)

\section{CASE OF MELENA.}

By C. R. Bre e, M.R.C.S.E., Stowmarket.

William $S$., aged 25, a gentleman's servant, of slight make, sallow complexion, and general nuluenlthy cachectic appearance, was attacked on Sunday, July 6th, with faintness, giddiness, a difficulty of expiration, and a sense of sinking in the epigastric region. When I 
saw him, soon after the commencement of the attack, he complained in addition to the above symptons of coldness and shivering; his tongue was white; intellect dull; pulse quick and wiry; and the bowels had been acted upon twice in the course of the few lours preceding my visit.

Upon iuquiry I found that he had frequently complained of pain in the epigastric region during the last six months, and that his bowels had been irregular, and his appetite variable. The week previous to his attack he had been engaged in the hay-field, but had not taken an excess of beer. Considering the case one of diseased stomach and bowels, I prescribed-

R. Hydrg. cum creta, gr. iv.; Pulv. Doverii, gr. vj.; M. Fiat pulv. horâ somni sumendus.

R. Sodæ Carb., Cretæ præp., utrq. dr. j.; Confect. Aromat. dr.j.; Sp. Ammon. Co., dr.j.; Aquæ Cinnam., oz. viij. M. Fiat mistura; sum. oz. iss. tertiis horis.

July 7 th. He appeared better in every respect this morning; his tongue was rather furred, and he con-. plained of thirst; pulse still quick, and countenance pallid. I ordered small doses of Hydrarg. cum creta and Dover's powder every six hours, and an effervescing dranght every three hours.

8th. Has had the bowels relieved twice; the evacuations were described to me as of a sooty blackness; complains more of faintness.

In the evening I was summoned in consequence of his being suddenly seized with sickness; the matter romited resembling coffee grounds, with small clots of blood in it. He was sitting on the side of the bed; face pale; lips bloodless; countenance anxious; pulse small and quick; no pain, but great sense of faintness. Two draughts with tincture of opium and acetate of lead with acetic acid secured a good night, with no return of romiting.

9 th. No return of sickness; no evacuation from the bowels; other symptoms much the same.

10 th. All the symptoms much the same as yesterday; no vomiting, and the bowels have not been moved. I prescribed two drachms of custor oil, with ten drops of tincture of opium, in a mixture every three hours.

11th. The castor-oil mixture has operated three times; the motions are copious, of a dark sooty black colour, and very offensive. He complains much of faintness; the face is pale; he has a disinclination for food, and feels sick, but has not vomited; pulse quick; urine free and normal. I ordered five minims of the oil of turpentine, and three of liquor opii sedativus, in a mixture with white of egg, every two hours.

12 th. Has been able to retain the medicine, which has been given regularly every two hours; has had no further evacuation or vomiting, but the general symptoms of faintness, quickness of pulse, and anxiety of countenance, are not relieved. He says he thinks the next dose of the turpentine mixture will make him sick; I therefore ordered a saline mixture to be substituted.

13th. Much the same; no further evacuation; the pulse is quick, jerking, and each second beat is prolonged so as to give it a peculiar character; still complains of a faint sinking sensation in the epigastrium; no tumefaction of the abdomen or tenderness; feels sick; no inclination for food; tongue pallid and slightly furred. Continue the saline mixture, with the addition of two grains of carbonate of ammonia in each dose.

14th. No better; bowels still confined; has romited some bilious matter; in other respects much the same. To continue the saline mixture and ammonia julep, and to bave an enema, with half an ounce of the oil of turpentine, if the bowels do not act in a few hours.

Vespere.-More faint and ill in every respect; the bowels not having been relieved, they administered an enema, which brought away a very copious dark sooty motion, after which he felt relieved.

15th. He is much more cheerful, and expresses himself as feeling altogether better this morning; the pulse still quick and hard, but the second beat not 80 much prolonged; face and lips very pallid; tongue pallid, and furred in the centre; bowels not moved in the night.

To have strong beef tea.

R. Sodæ Carbon., dr. j.; Ammon. Carbon., scr. j. ; dquæ Menthæ, oz. iv. Fiat mistura ; sum. cochl. j., magn. tertiis horis.

16 th. Much the same in every respect as yesterday.

17th. Passed a pretty good night, and remains much the same as yesterday, except having rather more thirst. Repeated the turpentine enema, which relieved the bowels; motion more solid and not quite so dark in colour.

18th. Complains this morning of a slight return of weight in the chest, rather higher than in the former instance; in other respects better.

R. Pulv. Rhei., gr. xviij.; Potassæ Sulph., scr. ij. M. Fiat pulv. vj.; sumat j. ex aqua quartis horis.

19th. Passed a pretty good night, more cheerful, pulse better; appetite also improved; has lost the weight in his chest, and feels considerably less thirst ; bowels relieved in the evening, motions inproving both in colour and consistence.

20th. Says last night was the best he has had since his illness; bowels relieved again this morning, since which he has complained of feeling rery faint; pulse weak.

R, Ammon. Sesqui-carb., dr. ss.; Tinct. Card. Co., dr. iij.; Aquæe ad oz. iv. Fiat mistura ; sum. cochl. magn. $\mathbf{j}$. quartis horis.

2lst. He is going on very well; has had one solid motion this morning, which caused him a good deal of pain in passing; it was of a brown colour, gradually assuming the natural character; tongue cleaning; pulse 80 , and soft ; is gaining strength.

Rept. mistura et Pulvis Rhei salinus sextis horis.

From this period he gradually recovered; his convaleacence was slow, but materially assisted by alkalies, vegetable tonics, and a generous diet. Within the last fortnight he has again undertaken the duties of his situation.

Some doubt has existed upon the propriety of separating melæna from hæmatemesis, and little practical importance has been attached to the necessity of distinguishing between the two diseases by medical writers. If we confine the term hæmatemesis to a maniting of blood from the stomach, perhaps the best diagnostic symptom is the precedence of the vomiting to the dark evacuations from the bowels. In the above case the sooty stools preceeded the vomiting several hours certainly, and probably two daya, as by a 
reference to the report it will be found thint diarrhcea was an early symptom on the 6 th, although the motions were not examined until the $8 \mathrm{th}$, on the evening of which day the first attack of vomiting occurred. Distinguished then from hrmatemesis, in which danger is comparatively speaking rare, the above case assumes the character of one quite as frequently fatal, the Melana splenetica of Saurages; the Soecsims niger of Hoffman; the Melcena cruenta of Good, and becomes sufficiently interesting I think to be recorded among the practical papers of our Journal. With regard to the treatment of the case, it will be perceived that I was nore anxious to meet the symptoms ds, they occurred, and assist nature in perfecting ber own cure, than to prescribe for the assumed plrenomena of a disease, the pathology of which, notwithstanding the researclies of Portal and others, still remains in considerable obscurity. I think the turpentine was of service, although only given in a quarter of the dose advised by Dr. Elliotson.

Stowmarket, October 24, 1845.

\section{DR. SHEARMAN'S CASE OF MALFORMATION OF THE HEART.}

TO THE EDITOR OF THE PROVINCIAL MEDICAL AND Str, SURGICAL JOURNAL.

Will you kindly allow me to ask of Dr. Shearman, through the mediun of your pages, some questions relative to his case of inalformation of the heart, reported in the Journal of July 30, 1845 ?

It appears that the pulmonary artery "was quite rudimentary ;" that into the left auricle only one very minute venous orifice could be found; and that there existed a largish venous trunk, communicating with the right auricle, and provided with a valve, which took "a circular course round the base of the heart." It appears further, that the little patient, in the space of a twelvemonth, had had several attacks of hæmoptysis, to the anount of froin one to two pints of "florid" blood each time; and that both lungs were tubercular. Dr. Shęarman asks whether this latter-state will account for the bremoptysis ? or if not, what was its cause?

I think it is important first to determine how the capilinaries of the pulmonary artery in the lungs were supplied with blood, since the trunk of the pulmopary artery was "quite rudimentary." Was the circulation carried on in a retrograde manner from the aorta througli the ductus arteriosus into the right and left pulmonary arteries? or was there any other mode of coipmunication between the right ventricle and the lungs ?

A g nin, how did the aerated blood find its way into the feft ventricle? Through the largish venous vessel wincting round the base of the heart? If not, whence did this winding vessel receive its blood?

With respect to the blowing sounds, Dr. Shearman's explanation of that heard at the ensiform cartilage, being due to tricuspid regurgitation, is quite satisfactory; the locality of the sound, and the time of its occuring, taken in connexion with the great jugular pulsation, sufficiently point out the lesion. That the systolic murmur over the sternum, near the third rib, was due to the meeting of the two stresins of blood, at the hole in the septum, appears more doubtful. I should bave thought that this was more likely to have caused the feeble bellows-sound at the apex; but then the former is to be accounted for. Now, I would ask Dr. Shearman, if, from the appearance of the aperture of the winding ressel and its valve in the auricle, there may not have been considerable regurgitatiou into this vessel at each ventricular contraction, and whether this may not have given the sonnd deemed to indicate aortic disease?

This question is, of course, only to be determined by the correspondence, or otherwise, of the situation of this orifice with the situation of the murmur, and the admission or not of regurgitation through it.

If this ressel was the afferent of the aerated blood from the lungs, and these organs received their supply through the ductus acteriosus or any other brancli of the aorta, then the hremoptysis is fully accounted for; for the lungs are injected by both ventricles at once through the aorta; while, in consequence of the free tricuspid regurgitation, and the supposed regurgitation through the peculiar valve, both ventricles in like inanner combine to inject the lungs through the winding "venous vessel." The lungs being thus injected through both the arterial and venous trunks; by the united force in each case of both ventricles, no wonder hæmoptysis was the result.

I trust Dr. Shearman will pardon the observations I have made, and the questions I have asked. I should not have taken this liberty but for the invitation with which he has been pleased to close his clear and simple statement of this very interesting case. If he would give the subject any further consideration, and communicate the result in the Journal, I should feel greatly obliged, and I hope you, Sir, would not think your space unprofitably occupied.

I am, Sir,

Your obedient servant,

Yeovil, Oct. 22, 1845.

F. NESBITT.

\section{UNIVERSITY COLLEGE HOSPITAL.}

\section{CASE OF SUB-ACUTE GASTRITIS.}

Reported by Mr. John Elliotr Wood, late Clinical Clerk in the Hospital.

Elizabeth Jones, aged 27, single, was admitted under Dr. A. 'T. Thoinsun, April 30, 1845. She is of middle height, sanguine tempersment, and fair complexion. She has been a housemaid for the last seven years, living in an open and airy siturtion in Landon, and always having a sufficiency of food and clothing. Her health has always been good till the present attack; she has never suffered from any acute disease, and not been subject to dyspepsin. On examination at the time of her admission into the hospital, it was ascertained that the present attack commenced two months ago, with giddiness in the head, sickness, loss of appetite, and pain in the region of the lumbar vertebra; these symptoms increased, and she soon felt a disinclination to take anything but acids. About three weeks ago she began to throw up whatever she took, and since that time she has been unable to keep anything on her stomach. At present, (A pril 30th,) she vomits continually, complains of pain on pressure at the epigastrium, with great prostration "of strength; 